\title{
THE EVALUATION OF PROPERTIES OF MECHANICALLY CLINCHED JOINTS MADE OF FERROUS AND NON-FERROUS MATERIALS
}

\author{
Luboš Kaščák' ', Emil Spišák', René Kubík', Janka Majerníková1 \\ 1 Technical University of Košice, Faculty of Mechanical Engineering, Institute of Technology and Material \\ Engineering, Letná 9, 04200 Košice, Slovakia, e-mail: lubos.kascak@tuke.sk, emil.spisak@tuke.sk, \\ rene.kubik@tuke.sk, janka.majernikova@tuke.sk
}

Received: 2018.01.09

Accepted: 2018.02.01

Published: 2018.03.01

\begin{abstract}
Nowadays, there are several reasons for the utilization of the sheets made of aluminum in the car body production. Besides decreasing the car body weight, there is a need to reduce fuel consumption of the vehicle as well as the environmental impact by lower production of emissions. Moreover, such reasons are mutually dependent or influence each other. The application of the aluminum sheets in hybrid car body production resulted in the need for innovative joining techniques, which could make it possible to successfully join sheets from aluminum alloys. Mechanical clinching is one of the new or innovative joining techniques, which belongs to cold-forming joining process, which makes it possible to join different kinds and thicknesses of sheets. Individual materials and thicknesses can be combined. The mechanically clinched joints are durable, and the joining process duration is very fast (duration of $1 \mathrm{~s}$ ) and does not have a distinctive impact on the environment; a protective layer of the sheets remains intact. The paper focuses on the evaluation of the properties of hybrid joints that were prepared by the single stroke clinching process with a rigid die. The hot-dip galvanized steel sheets DC06 and H220PD combined with the sheets from aluminum alloys EN AW 5754 (having different values of the hardness - H11, H22, and H24) and EN AW 6082 were used for joining. The results from experiments confirmed the mechanical clinching is the suitable technique for joining such combination of sheets. However, some considerations, such as the arrangement of the sheets about the punch and die, must be regarded.
\end{abstract}

Keywords: clinching, aluminum alloy, steel sheets, tensile test.

\section{INTRODUCTION}

The structure of the modern hybrid car body consists of ultra-high strength steel sheets, the sheets from aluminum alloys, magnesium alloys and carbon fibers [1]. The example of a typical hybrid car body, representing the body of Audi A8, is shown in Figure 1. The hybrid car body is a complex construction, including many materials which are designed for a specific purpose. However, the utilization of modern, progressive and high-strength materials lead to the specific problems about their joining. A question relat- ed to joining of materials of a different kind is their different properties at elevated temperatures when conventional joining methods such as the resistance spot welding cannot be utilized [2-4].

Therefore, new and innovative joining techniques are required for joining such combination of steel and aluminum sheets in general [5]. The main problem of joining steel and aluminum sheets is in their different level of the melting temperatures and the presence of the surface oxide layer high heat conductivity (in the case of aluminum) hence they are difficult to weld. To overcome the problems related to joining of 


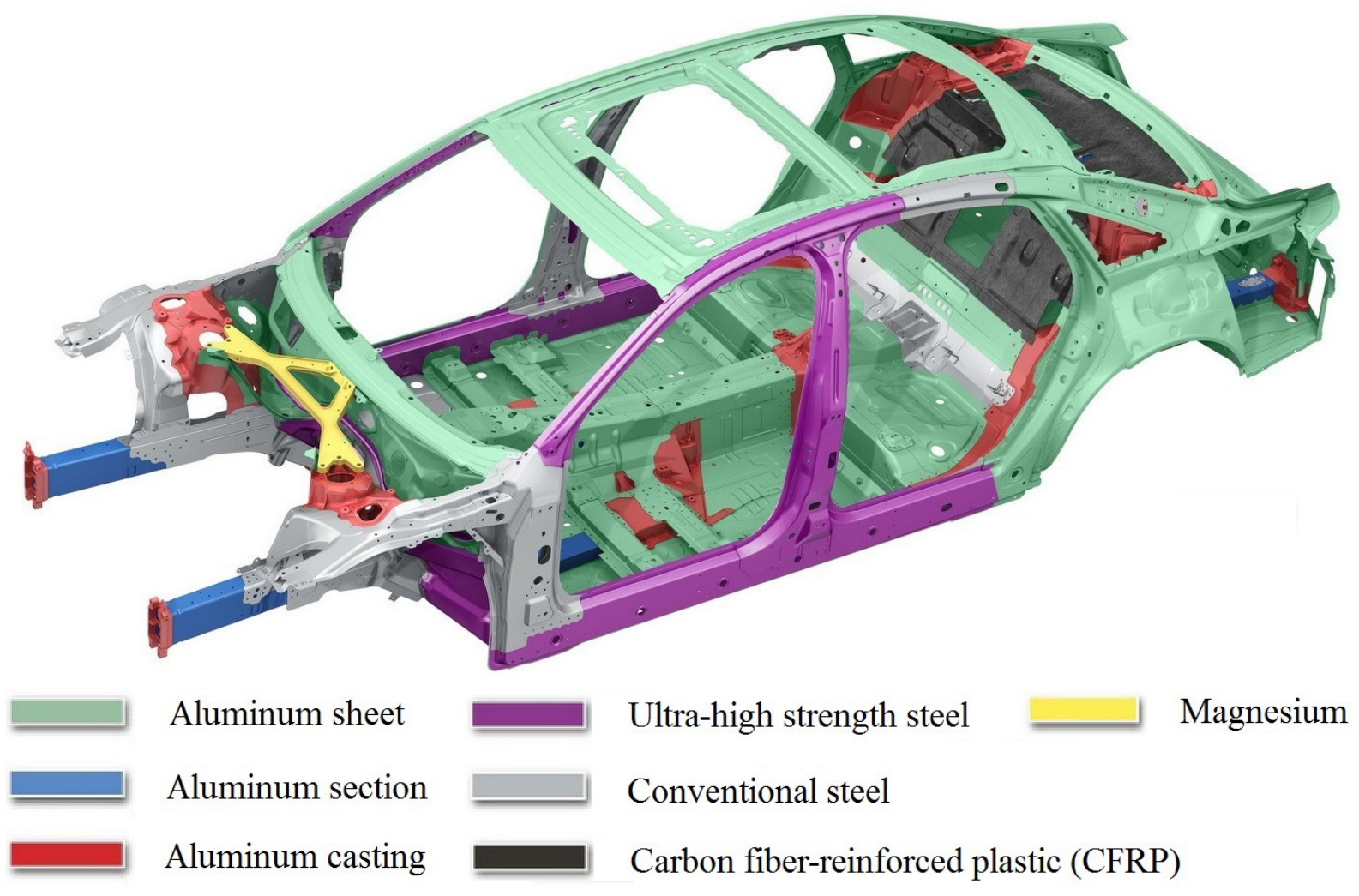

Figure 1 The utilization of aluminum in hybrid car body (Audi A8) [2]

above-mentioned combination, a certain amount of innovative mechanical joining techniques were developed: self-pierce riveting, mechanical clinching, clinch-riveting and other processes. As resulting from the extensive scientific work, that mechanical clinching is a suitable joining technique for joining the lightweight steel sheets $[6,7]$. Besides mechanical clinching, the friction stir welding or adhesive bonding could be utilized when joining aluminum and steel sheets [8]. Scientific research and development have confirmed that the utilization of the mechanical clinching brings new possibilities for the production of the hybrid car bodies (sometimes referred to as multimaterial car bodies) consisting of the lightweight materials [9]. Besides the aluminum, mechanical clinching could be applied for joining magnesium alloys, even for its combination with different materials. However, the proper mechanically clinched joints (made of the magnesium alloys) are produced under elevated temperature conditions, when the process temperature reaches about $220^{\circ} \mathrm{C}[10,11]$. The scientific research and development continuously effort to apply the mechanical clinching for a wide range of materials, such as the textile-reinforced thermoplastics, or the carbon fiber reinforced polymers as a standard material suitable for this joining $[12,13]$.
Mechanical clinching rests in the development of a mechanical interlock between two or more sheet materials by the action of a punch and a die [14]. There are various concepts of tools and processes which are used in the mechanical clinching, but the general classification criterion could divide the mechanical clinching into two groups: cutting and non-cutting mechanical clinching [15]. The main difference between these two groups rests in the shape of the resulting mechanically clinched joint (which can be circular and rectangular) and the referring shape of the tools required. The clinched joints and the corresponding tools for the cutting and noncutting mechanical clinching are shown in the Fig. 2a and 2b.

When joining the sheet materials by the cutting mechanical clinching, the downward movement of a punch results in the partial cutting of both joined sheet materials. This cutting takes place in the direction of the longer edges of both tools. The stamping and bottom pressing of both sheets take place right after the cutting process. The die has flexible segments, which move in the radial direction along the material flow in the radial direction which is induced by the movement of a punch [16]. 


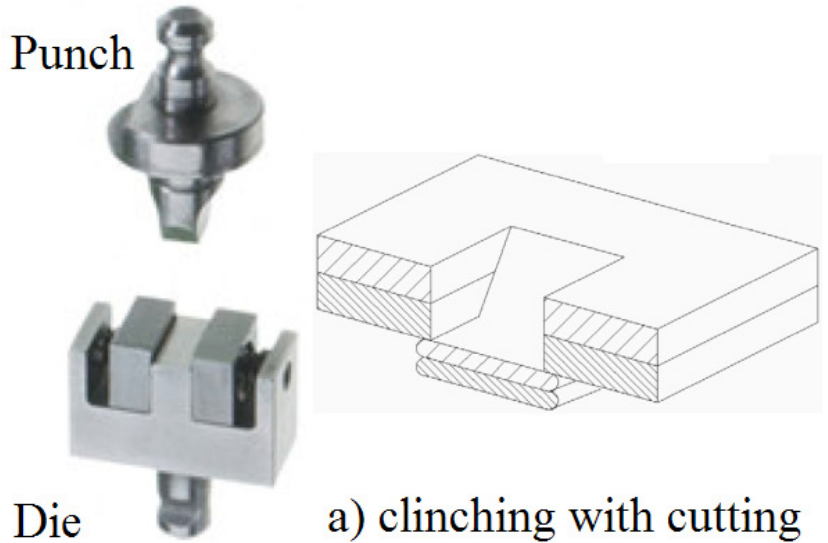

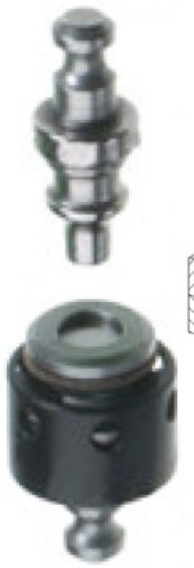

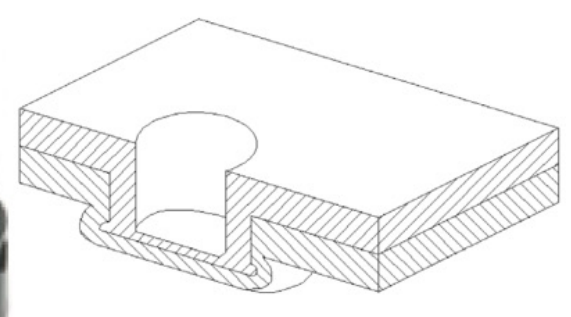

b) non-cutting clinching

Figure 2. The cutting (a) and non-cutting (b) mechanical Clinching [9]

On the other hand, no shearing of the joined sheet materials takes place in the non-cutting mechanical clinching. However, the non-cutting method involves severe plastic deformation of both joined sheets [18]. This type of the clinching technique consists of four stages: clamping, pressing, bottom pressing and interlock forming. These stages are shown in Fig. 3. The forming force is applied through the punch, moves downwards and draws both (or more) sheet materials into the rigid die cavity. The cavity has specifically designed its contour to create the interlock between the upper and the lower sheet material. However, when joining materials with insufficient or limited formability, some design changes are required [19]. Some changes of the geometry of the tool (punch or die) based on the results of FEA are done, which improve the material flow and interlocking in the joint forming process. Moreover, the mechanical clinching process was improved in the mode of thermally assisted plastic deformation of the sheets due to the low formability of some thin "difficult to join" sheet materials at room temperature [20]. New and improved mechanical clinching concepts are constantly developed according to the specific sheet materials joined.

The paper deals with the evaluation of the properties of joints of hot-dip galvanized steel sheets DC06 and H220PD combined with the sheets from aluminum alloys EN AW 5754 and EN AW 6082, prepared by the single stroke clinching process with a rigid die.

\section{MATERIAL AND METHODS FOR EXPERIMENTS}

A non-cutting mechanical clinching with rigid die (the process is shown in Figure 3) was utilized for the preparation of the mechanically clinched round joints. Mechanically clinched joints were

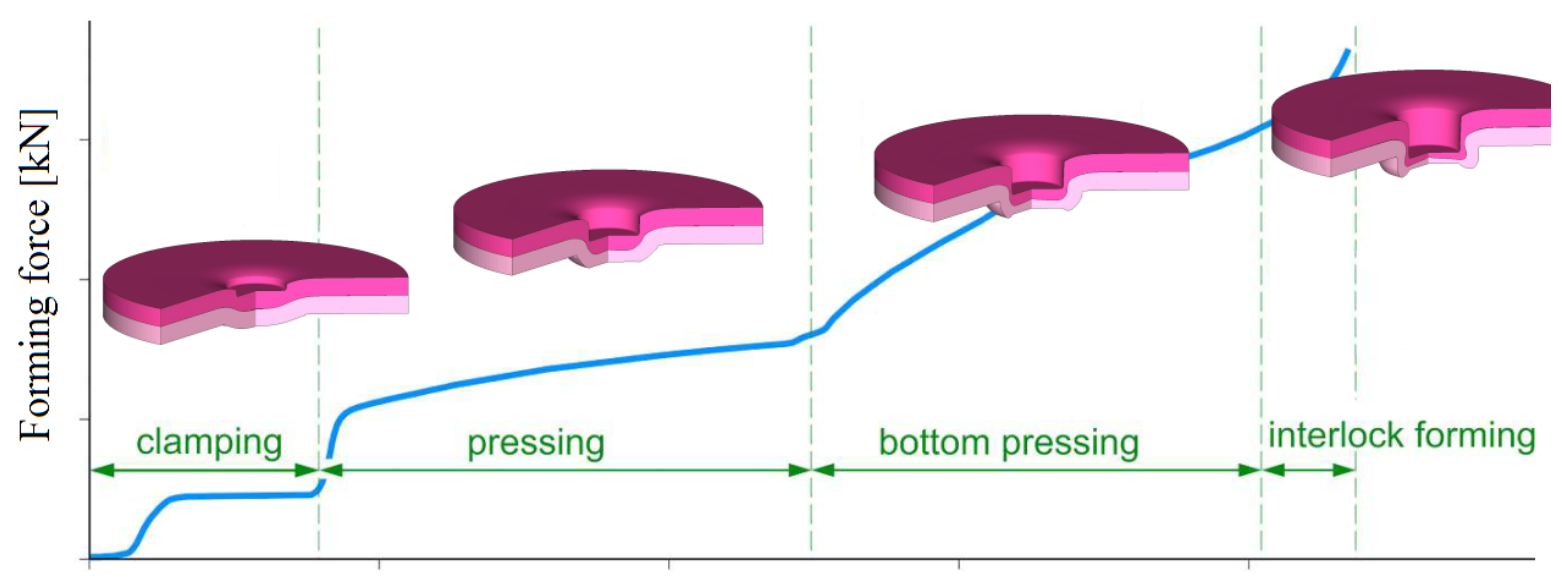

Punch displacement [mm]

Figure 3. Forming a clinched joint with the development of forming force [18] 
produced by combining two types of the hot-dip galvanized steel sheets: DC06 - deep drawing steel and H220PD - High-Strength Low-Alloy (HSLA) steel and four types of the aluminum alloy sheets: AW 5754 - H11, H22, H24 and AW 6082 T6. The basic mechanical properties, along with their thickness are shown in Table 1.

Mechanically clinched joints can be prepared in two manners when the arrangement of both sheets is considered, because various parameters (the load-bearing capacity of the clinched joint, or the joinability of the sheets) are subsequently affected. This is important especially in the case of "difficult to join" sheet materials because the arrangement (punch-sided material, die-sided material) of the joined material influences the load-bearing capacity of the clinched joint. For the experiment, various material combinations were chosen. Table 2 shows the material combinations chosen for the clinching; which sheet ma- terial was arranged on the punch side and which material was arranged on the die side. Such sheet material combinations make it possible to determine the appropriate solution if the arrangement (or position) of the specific material (steel or aluminum alloy) about the punch is considered.

All of the mentioned materials were prepared for the experiments according to STN 051122 standard, which defines the dimensions of testing samples subjected to the tensile (shear) loading (Fig. 4a). All mechanically clinched joints were tensile-shear tested to determine the load-bearing capacity of individual joints in relation to their arrangement (punch sided, die sided) during clinching. The tests were carried out on the tensile testing machine TIRAtest 2300 to determine the maximum force needed for the rupture of mechanically clinched joints. The characteristic values of clinched joint which affect its the loadbearing capacity are shown in Fig. 4b.

Table 1. Basic mechanical properties of joined materials

\begin{tabular}{|c|c|c|c|c|c|}
\hline Sheet material & $\mathrm{t}[\mathrm{mm}]$ & $\mathrm{Rp}_{0.2}[\mathrm{MPa}]$ & $\mathrm{Rm}$ [MPa] & $\mathrm{A}_{80}[\%]$ & $\mathrm{n}[-]$ \\
\hline DC06 & \multirow{2}{*}{0.8} & 170 & 305 & 41 & 0.26 \\
\hline H220PD & & 238 & 382 & 36 & 0.24 \\
\hline AW 6082 T6 & 0.9 & 313 & 341 & 12 & 0.09 \\
\hline AW 5754 H11 & \multirow{3}{*}{0.8} & 137 & 221 & 25 & 0.28 \\
\hline AW 5754 H22 & & 160 & 246 & 20 & 0.19 \\
\hline AW 5754 H24 & & 138 & 141 & 6 & 0.13 \\
\hline
\end{tabular}

Table 2. Material combinations of steel and aluminum alloy sheets

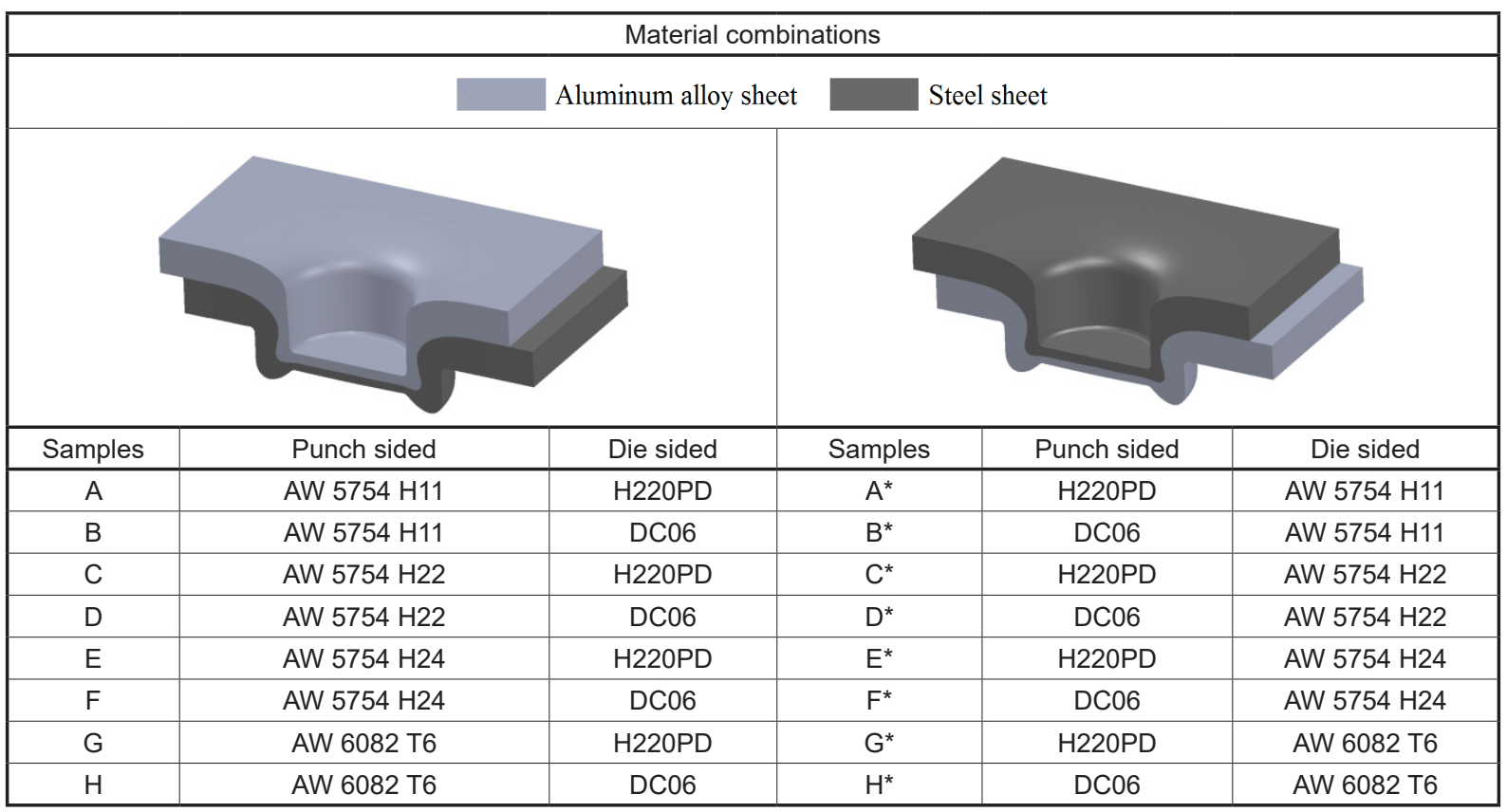


a)

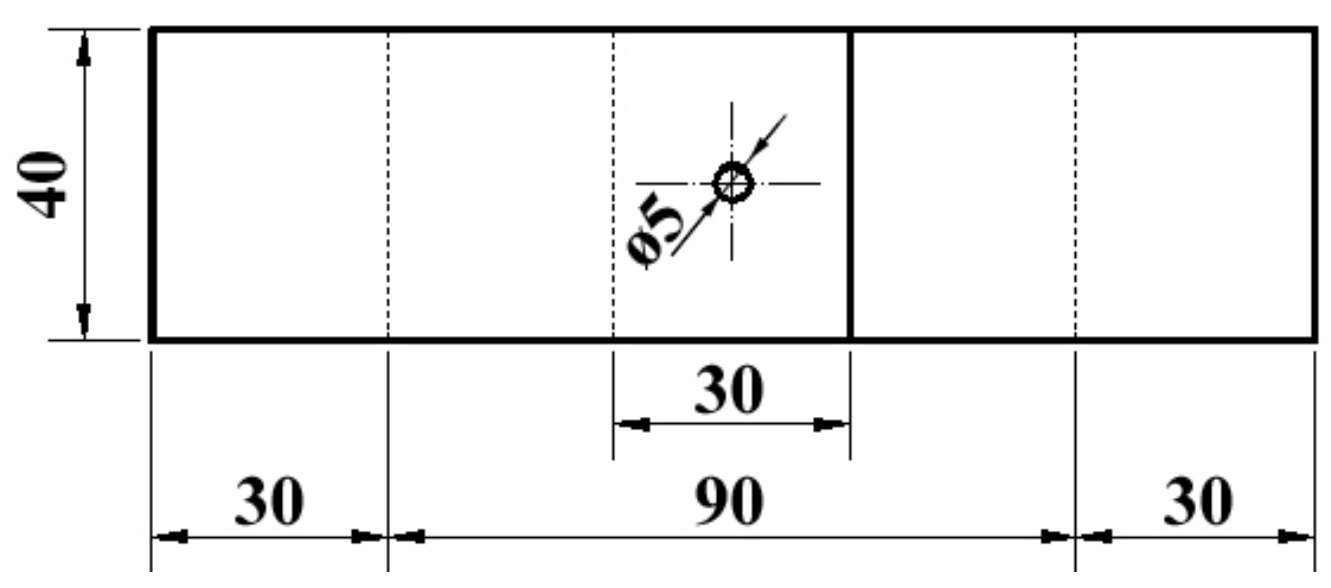

b)

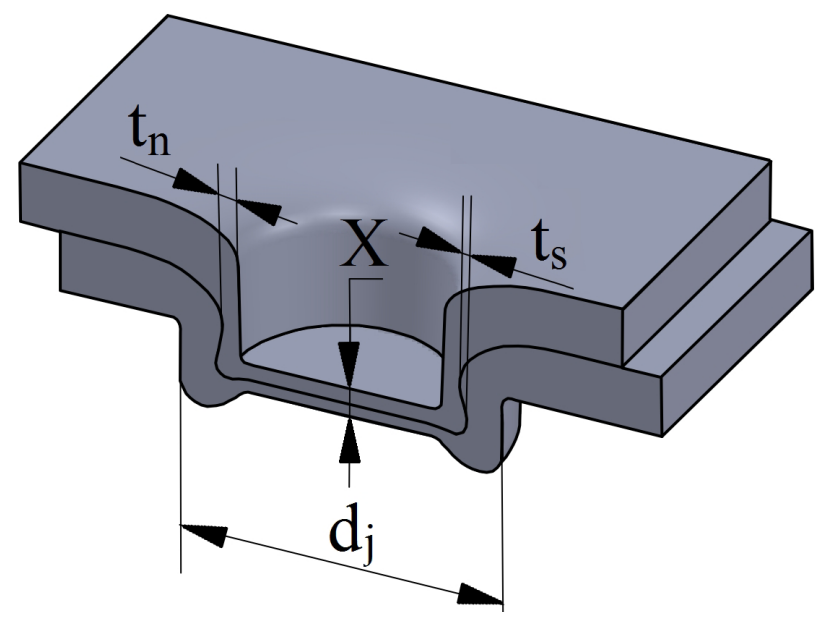

\section{$\mathrm{t}_{\mathrm{n}}$ - neck thickness}

$\mathrm{t}_{\mathrm{s}}$ - undercut $\mathrm{X}$ - bottom thickness $\mathrm{d}_{\mathrm{j}}$ - joint diameter

Figure 4. a) Specimen dimensions and b) parameters of the mechanically clinched joint

\section{RESULTS AND DISCUSSION}

The results of tensile-shear test of the mechanically clinched joints provided various observations: the maximum shear force needed to rupture the clinched joint, the behaviour of the joint under static loading, the failure mode of the clinched joint (neck fracture mode, or pull-out mode) and the suitability of specific sheet material (steel or aluminum alloy) for the arrangement on the side of punch or die.

The differences among samples were observed mainly in the interlocking area - in neck thickness $\left(t_{n}\right)$ and undercut $\left(t_{s}\right)$ area. The measured values of neck thicknesses and undercuts are shown in Table 3.

The results from the tensile-shear test for the samples $\mathrm{A} / \mathrm{A}^{*}, \mathrm{~B} / \mathrm{B}^{*}, \mathrm{C} / \mathrm{C}^{*}$ and $\mathrm{D} / \mathrm{D}^{*}$ are shown in Fig. 5. The graphs present the forms of curves when the steel sheet was oriented on the punch side or the die side.

For the material combinations shown in Fig. 5, the highest load-bearing capacities were measured when the steel sheets (DC06 or H220PD) were arranged on the punch side. The values of loadbearing capacity ranged from $1050 \mathrm{~N}$ to $1100 \mathrm{~N}$.

The undercut values $\left(\mathrm{t}_{\mathrm{s}}\right)$ were about $40 \%$ higher than the undercut values measured when the aluminum alloy sheets (AW $5754 \mathrm{H} 11$ and AW $5754 \mathrm{H} 22$ ) were arranged on the punch side. The values of the load-bearing capacity for the sheet form aluminum alloy on the punch side ranged from $440 \mathrm{~N}$ to $610 \mathrm{~N}$. The significant low values of the undercut $\left(\mathrm{t}_{\mathrm{s}}\right)$ were measured for this sheet material arrangement. Both failure modes (pull-out and neck fracture mode) were observed on the joints after the tensile-shear test.

The results of the tensile-shear test for the samples $\mathrm{E}^{*}, \mathrm{~F} / \mathrm{F}^{*}, \mathrm{G} / \mathrm{G}^{*}$ and $\mathrm{H} / \mathrm{H}^{*}$ are shown in Fig. 6. The curve of sample $\mathrm{E}$ (combination of EN AW 5754 H24 and H220PD) is not signed in the graph, since the clinched joints were not successfully formed. The low mechanical properties of the aluminum sheet AW 5754 H24 caused a failure of the clinch joint during the clinching process. Authors [21] identified the main phases in which clinching develops: offsetting, upsetting and flow pressing. The offsetting phase is 
Table 3. The characteristic values of clinched joints (in $\mathrm{mm}$ )

\begin{tabular}{|c|c|c|c|c|c|}
\hline Samples & Neck thickness $t_{n}$ & Undercut $t_{s}$ & Samples & Neck thickness $t_{n}$ & Undercut $_{s}$ \\
\hline A & 0.178 & 0.061 & $\mathrm{~A}^{*}$ & 0.187 & 0.156 \\
\hline $\mathrm{B}$ & 0.315 & 0.019 & $\mathrm{~B}^{*}$ & 0.396 & 0.047 \\
\hline C & 0.183 & 0.083 & $\mathrm{C}^{*}$ & 0.188 & 0.210 \\
\hline $\mathrm{D}$ & 0.285 & 0.054 & $\mathrm{D}^{*}$ & 0.318 & 0.092 \\
\hline $\mathrm{E}$ & not measured & not measured & $\mathrm{E}^{*}$ & 0.180 & 0.145 \\
\hline $\mathrm{F}$ & 0.362 & 0.024 & $\mathrm{~F}^{*}$ & 0.387 & 0.037 \\
\hline $\mathrm{H}$ & 0.180 & 0.075 & $\mathrm{G}^{*}$ & 0.145 & 0.105 \\
\hline
\end{tabular}
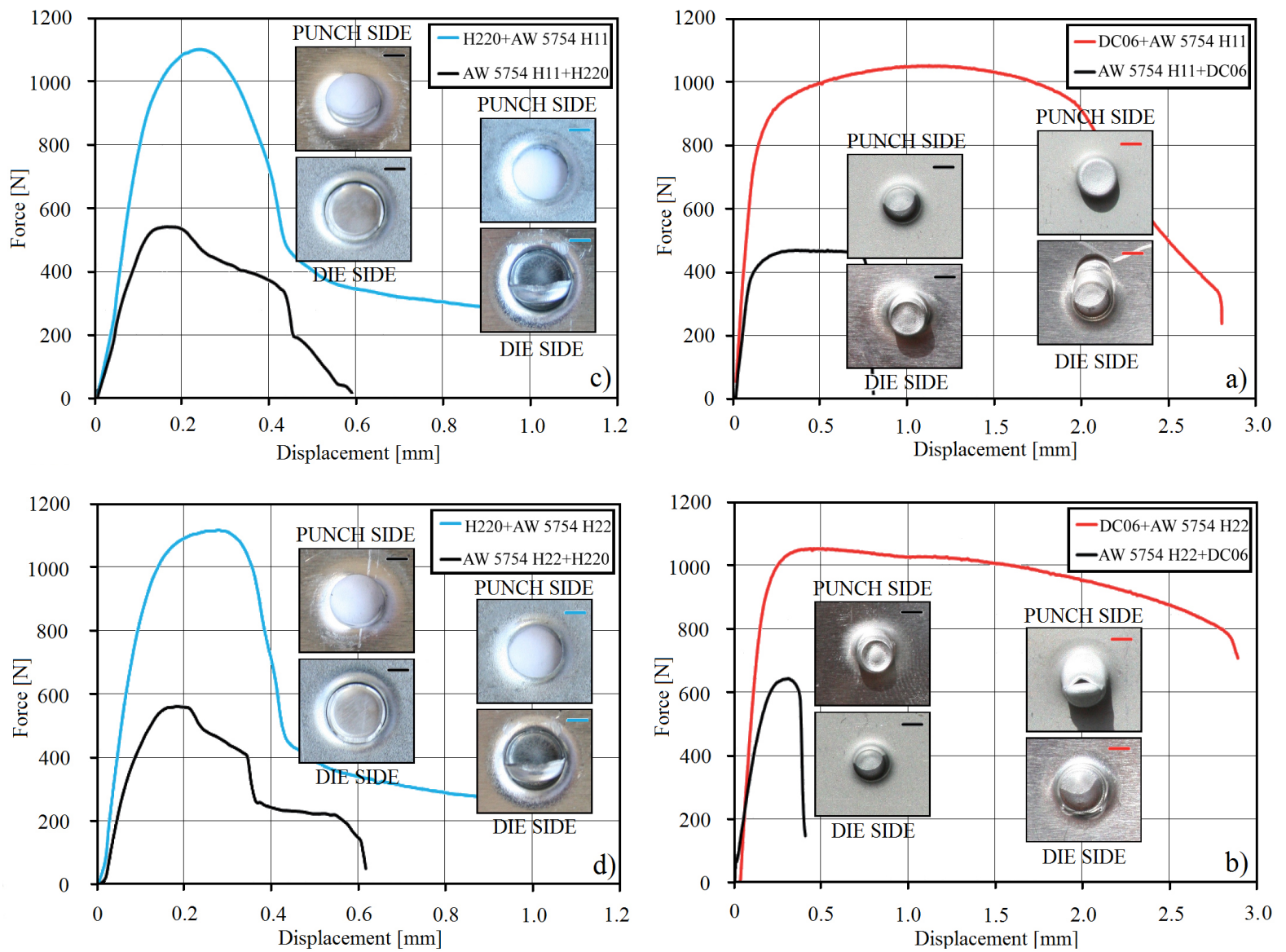

Figure 5. The results of tensile test of clinched joints:

a) samples $\left.A / A^{*}, b\right)$ samples $B / B^{*}$, c) samples $C / C^{*}$, d) samples $D / D^{*}$

characteristic by reduction of the thickness of the material wall around the punch. It leads to the increasing of material flow during upsetting phase and flow pressing. Considering the value of yield stress and low ductility of AW 5754 H24 sheet, the phase of flow pressing during clinching was completed prematurely due to restricted material flow. The low ductility of a joined sheets influences their ability to stretch without fracturing.

The results measured for material combinations in Figure 6 were similar to the results showed in Figure 5. There was one exception in the case of the material combination in sample $\mathrm{H}$ (AW 6082+DC06) where the higher values of load-bearing capacity were measured for the aluminum alloy sheet arranged on the punch side. These samples sowed higher values of undercut $\left(t_{s}\right)$ than samples $H^{*}(D C 06+$ AW 6082).

Metallographic observations were carried out to observe structures of the mechanically clinched joints for any discontinuities that could negatively affect the joint's load-bearing capacity. More- 

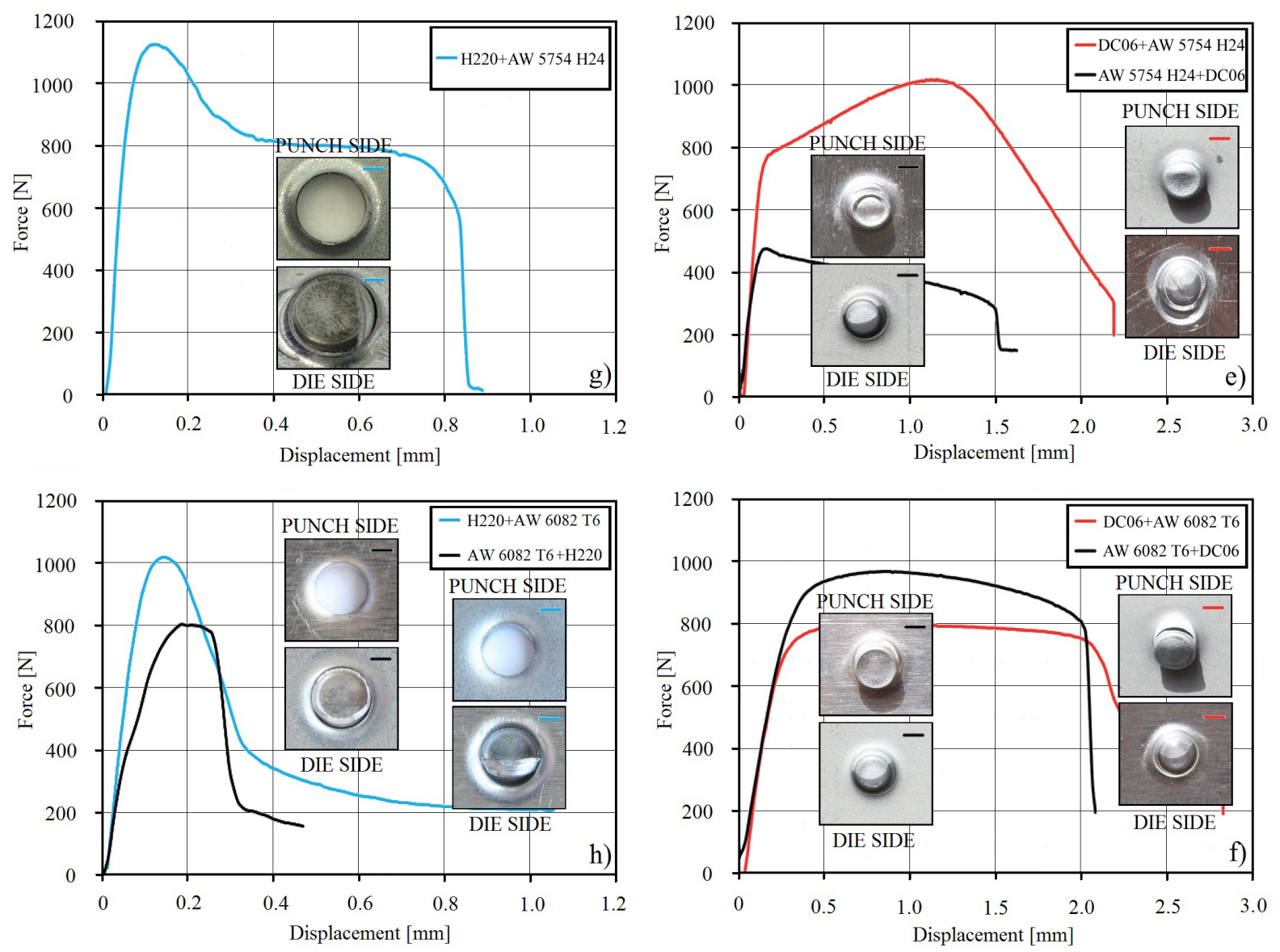

Figure 6. The results of tensile test of clinched joints: a) sample $E^{*}$, b) samples $\left.F / F^{*}, c\right)$ samples $G / G^{*}$, d) samples $\mathrm{H} / \mathrm{H}^{*}$

over, metallographic cross-sections were utilized for the measurement of the neck thickness $\left(t_{n}\right)$ and the undercut $\left(\mathrm{t}_{\mathrm{s}}\right)$. Figure 7 shows the measurement of $t_{n}$ and $t_{s}$ on the following cross-sections (material combinations): sample $\mathrm{B}^{*}(\mathrm{a} 1, \mathrm{a} 2)$, sample B (b1, b2), sample $\mathrm{H}^{*}(\mathrm{c} 1, \mathrm{c} 2)$ and sample $\mathrm{H}(\mathrm{d} 1$, d2). Metallographic observation confirmed the suitability of clinching as a joining technique for material combinations of both steel sheets with the observed aluminium alloys. No cracks or failures occurred during the joining process, except the above mentioned sample $\mathrm{E}$.

\section{CONCLUSIONS}

Mechanical clinching is a suitable technique for joining the observed combination of materials that are utilized in the hybrid car body. However, the proper arrangement of the sheet materials (punch sided, die sided material) should be taken into account when the load-bearing capacity of the mechanically clinched joint is the important characteristic.
In this study, the mechanically clinched joints were prepared by the combination of DC06 (deep drawing steel), H220PD (HSLA steel), AW 5754 (H11, H22, and H24) and AW 6082 T6 (aluminum alloys) materials. The test results showed that individual material combinations could be successfully clinched, but the arrangement of the aluminum alloy sheet materials on the punch side results in the lower load-bearing capacity of mechanically clinched joint when compared to the one with the arrangement of the steel sheet material on the punch side. Such joints (with aluminum alloy sheet material arranged on the punch side) have lower load-bearing capacity, which reaches about $50 \%$ of the load-bearing capacity of a joint with the steel sheet (DC06 or H220PD) arranged on the punch side. There was a difference in the failure mechanism of mechanically clinched joints when subjected to tensile-shear loading. The joints made of deep drawing steel (DC06) failed by the pull-out mode, regardless of the arrangement of the materials. The joints made of HSLA steel (H220PD) failed by the neck fracture mode, regardless of the arrangement of 


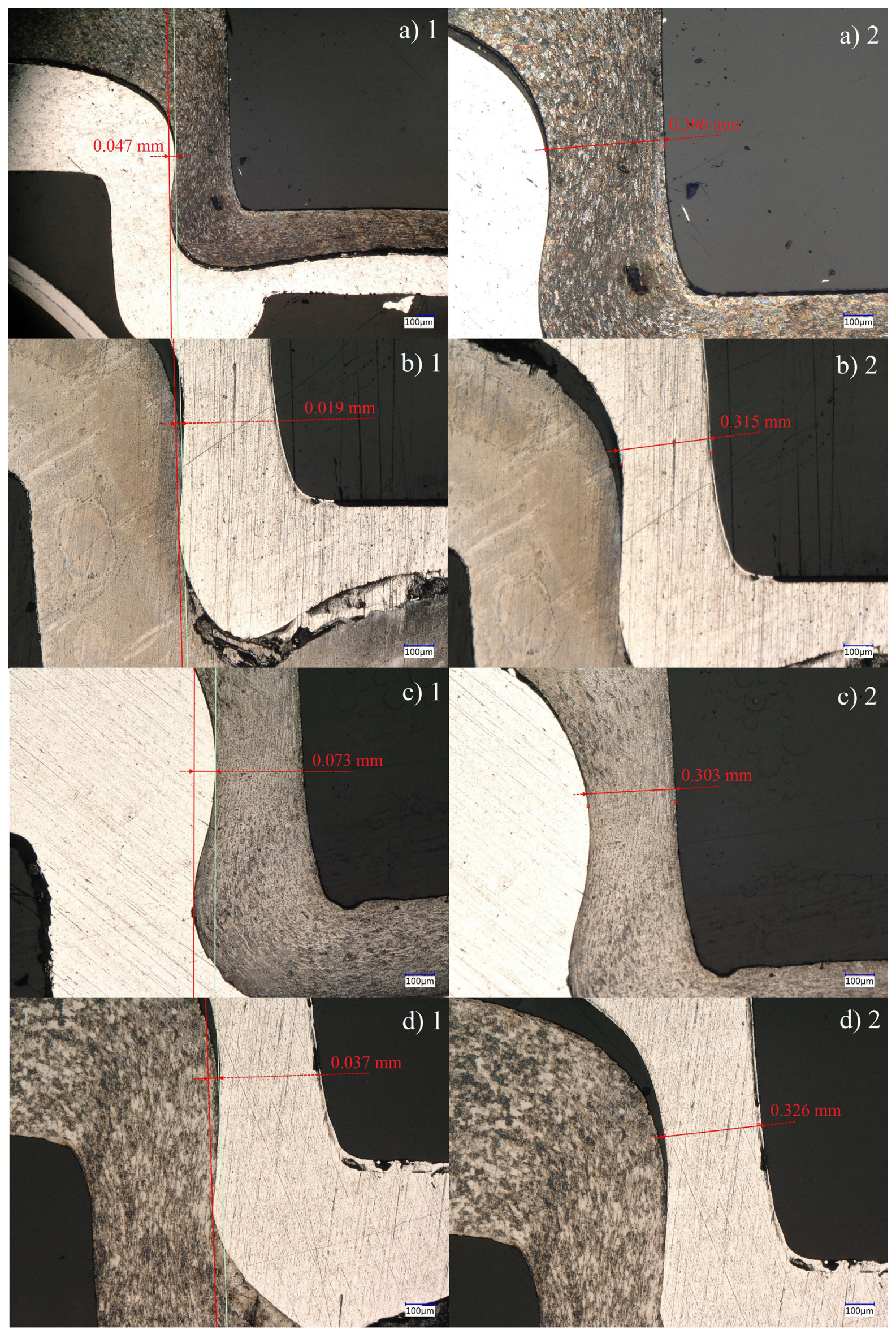

Figure 7. Measurement of the undercut $\left(t_{s}\right)$ and the neck thickness $\left(t_{n}\right)$ : a) sample $\left.B^{*}, b\right)$ sample $B$, c) sample $H^{*}$ and d) sample $\mathrm{H}$ 
the materials. Metallographic observations and measurements of the neck thickness and the undercut of individual mechanically clinched joints confirmed low values of the undercut $\left(t_{s}\right)$ when aluminum alloy sheet material was arranged on the punch side; except the sample $\mathrm{H}$ with AW 6082 T6 sheet. These low values of the undercut parameter directly affect the load-bearing capacity of the joint when subjected to tensile-shear loading.

\section{Acknowledgements}

This work was supported by the Slovak Research and Development Agency under the Contract No. APVV-14-0834 and project VEGA No. $1 / 0441 / 17$.

\section{REFERENCES}

1. Monol S. S. and Ghosh S. A review of design and material selection for a hybrid vehicle. International Journal of Science and research, 5 (10), 2016, 1356-1364.

2. Kaščák L', Mucha J., Slota J. and Spišák E. Application of modern joining methods in car production. Oficyna Wydawnicza Politechniki Rzeszowskiej, 2013.

3. Spišák E. and Kaščák L'. Joining car body sheets using the clinching method. Acta Mechanica Slovaca, 15 (1), 2011, 28-35.

4. Eshtayeh M.M., Hrairi M. and Mohiuddin A.K.M. Clinching process for joining dissimilar materials: state of the art. International Journal of Advanced Manufacturing Technology, 82, 2016, 179-195.

5. Hörhold R., Müller M., Merklein M. and Meschut G. Specimen's geometry related influences on load-bearing capacity of joining aluminium and UHSS by innovative shear-clinching. Journal of Materials Science Research, 6 (4), 2017, 19-27.

6. Lambiase F., Paoletti A. and Di Ilio A. Advances in mechanical clinching: employment of a rotating tool. Proc. of $17^{\text {th }}$ International Conference on Sheet Metal (SHEMET17), Palermo, Italy 2017, 200-205.

7. Zhang Y., Shan H., Li Y., Guo J., Luo Z. and Ma Ch. Y. Joining aluminium alloy 5052 sheets via novel hybrid resistance spot clinching process. Materials and Design, 118 (17), 2017, 36-43.

8. Chen Ch., Zhao S., Cui M., Han X., Fan S. and Ishida T. An experimental study on the compressing forces for joining Al6061 sheets. Thin-Walled Structures, 108 (16), 2016, 56-63.
9. He X. Clinching for sheet materials. Science and Technology of Advanced Materials, 17 (1), 2017, 381-405.

10. Hahn O., Horstmann M. Mechanical joining of magnesium components by means of inductive heating. Material Science Forum, 2 (15), 2007, 539-543.

11. Hahn O., Tan Y., and Schroeder M. Thermally supported mechanical joining of magnesium components. Material Science Forum, 7 (15), 2005 , 488-489.

12. Gude M., Hufenbach W., Kupfer R., Freund A. and Vogel Ch. Development of novel form-locked joints for textile reinforced thermoplastics and metallic components. Journal of Materials Processing Technology, 216 (10), 2015, 140-145.

13. Lambiase F. and Ko D. Ch. Feasibility of mechanical clinching for joining aluminum AA6082-T6 and carbon fiber reinforced polymer sheets. Materials and Design, 107 (15) 2016, 341-352.

14. Lambiase F., Di Ilio A. and Paoletti A. Joining aluminum alloys with reduced ductility by mechanical clinching. International Journal of Advanced Manufacturing Technologies, 77 (12), 2015, 1295-1304.

15. Hörhold R., Müller M., Merklein M. and Meschut G. Mechanical properties of an innovative shearclinching technology for ultra-high strength steel and aluminum in lightweight car body structures. Weld World, 60 (13), 2016, 613-620.

16. Mucha J. The analysis of rectangular clinching joint in the shearing test. Maintenance and Reliability, 3 (17), 2011, 45-50.

17. Balawender T. Low fatigue strength of clinch joints. Journal of Mechanics Engineering and Automation, 6 (2), 2016, 277-281.

18. Krzton H., Mucha J. and Witkowski W. The application of laboratory X-ray micro-diffraction to study the effects of clinching process in steel sheets. Acta Physica Polonica A, 4 (130), 2016, 985-987.

19. Huang Z. and Yanagimoto J. Dissimilar joining of aluminum alloy and stainless steel thin sheets by thermally assisted plastic deformation. Journal of Materials Processing Technology, 225 (4), 2015, 393-404.

20. Abe Y., Kato T. and Mori K. Joining of highstrength steel and aluminum alloy sheets by mechanical clinching with dies for control of metal flow. Journal of Material Processing Technology, 212 (20), 2012, 884-889.

21. Israel M., Mauermann R. and Schellnock J. Thick sheet clinching - joining up to $20 \mathrm{~mm}$ total thickness, Advanced Shipping and Ocean Engineering, 2 (1), 2013, 1-10. 